\title{
General and Specific Conditions of Arbitration Agreement
}

\author{
Masoudreza Ranjbar ${ }^{1} \&$ Mehdi Dehshiri ${ }^{1}$ \\ ${ }^{1}$ Department of Law, Shiraz Branch, Islamic Azad University, Shiraz, Iran \\ Correspondence: Masoudreza Ranjbar, Department of Law, Shiraz Branch, Islamic Azad University, Shiraz, Iran. \\ E-mail: Masoudreza. Ranjbar@gmail.com
}

Received: August 16, 2017

doi:10.5539/jpl.v10n5p95
Accepted: September 21, $2017 \quad$ Online Published: November 29, 2017

URL: https://doi.org/10.5539/jpl.v10n5p95

\begin{abstract}
Arbitration as an alternative method of dispute resolution intrinsically is considered an exceptional institution. Being exceptional the arbitration institution requires to form it under the agreement of the will of the parties in the form of the arbitration agreement and thus until the parties have not agreed, Judgment is not imposed on them. Arbitration agreement is a contract in term of nature, and like all contacts must be respected the general rules of contract in it. The noteworthy point about this is that how is the observation of these conditions in arbitration agreement? In addition, this contract has the contents and conditions that the contracting parties agree to it and the basis of action of arbitrator or arbitrators is in the dispute settlement that it is interpreted as the specific conditions of the contract. The most important cases that often are noticed them in arbitration agreements and in the case of silence of the parties, the law governing the arbitration is replaced with their will in this regard, as follow: competence of arbitrator, language arbitration, the arbitration time, the arbitration costs, location of investigation and the number of arbitrators. The main question in this regard is this, how is the mutual consent of the parties of agreement in this regard. The answer to these two questions is the subject of this paper, which has been dealt with it through library studies and with the content analysis method.
\end{abstract}

Keywords: arbitration agreement, general conditions, specific conditions

\section{Introduction}

Government means most common or government with this task that has been assigned to it by the members of society is required to settle disputes arising from personal relationships in the society in order to establish order and justice. But individuals for reasons such as being expensive, time-consuming, openness, ceremonial and... Have preferred that resolve their disputes through non-governmental way and privately in the governmental proceeding and hence alternative methods of dispute settlement were emerged that arbitration is one of the most important ones. In the arbitration agreement, the parties agree that a judging organization or one or some natural person resolve their differences. In the Ad-hoc arbitration, the arbitrator or arbitrators when are obliged to arbitration that accept the arbitration; So the arbitration agreement is a commitment to the detriment of a third party toward arbitrator that it will be applicable only by his/her acceptance. In organizational arbitration, often because the arbitration organization has had the right and duty to investigate according to law, statute or convention that created, therefore, the agreement of the conflicting parties to arbitration through this arbitration organization is sufficient to oblige it to investigate. In other words, the arbitration organization before the agreement of the parties has stated its agreement to fulfill this commitment. The remarkable point about it is that range of subjects related to the arbitration has been expressed in the arbitration organizations by law, statute or convention related to it and persons can agree to the arbitration of that organization only in the determined range. For example, "International Centre for Settlement of Investment Disputes between states and nationals of other states" that it is mentioned as "ICSID", only settles the disputes of investment between investee country and foreign investor;sothe agreement to submission of the dispute of the determined off-topic, will not have affect practically and this center will not be obliged to investigate.

Being contractual the arbitration is due to being exceptional this institution that is taken into consideration in the legislative system of states, as well as International conventions relating to arbitration and being agreement the arbitration institute has been explicitly expressed in them. Since the arbitration has a contractual aspect and the basic conditions of accuracy of the transactions should be observed to form any contract, the arbitration agreement should also contain these conditions. Review these conditions in the arbitration agreement will be carried out in the first part of this article. Sovereignty principle of will requires that the specific conditions of the 
arbitration agreement in principle be determined by contracting parties, but in the legal systems of the country, there are also complementary rules that have been stated in some of the most important of these conditions in paragraph II of this article.

\section{General Conditions of Arbitration Agreement}

General conditions or in other words' general rules of contract are the same in all contracts. Conditions that involve all and universal are accepted by legal systems and their impairments in different systems follow guarantee of different performances. In Iranian law, Article 190 of the Civil Code has stated these conditions.

\subsection{Parties and Their Consent}

The basic element constituting each contract is the will of the parties. This issue is common in all legal systems (Pour Rashid, 2005: 107). Arbitration institution is also created based on the same principle by agreement the willingness of the parties to the dispute that want to settle their differences through arbitration, competence of the arbitrator (power and legitimacy) to resolve a dispute also is raised from this agreement (Chovancova, 2007: 990).

There are various ways to obtain three mentioned above introductions (existence, announcement and will agreement) in contracts. The legislator has required individuals to conclude some contracts to adopt the certain practice. In other words, it have violated the principle of being consensual the contracts and has turned them into ceremonial contracts so that in addition to offer and acceptance; involve another element in the creation of the contract. Writing the contract is one of these elements. Now the question is here that the arbitration agreement is classified contracts in which one of the contracts? Is it a constant contract that merely by agreement wills either in verbal or action way can be considered it as formed contract or writing is a condition for creation it and it is considered a ceremonial contract?

Taking the position of legal systems in this regard often is in the direction to the ceremonial arbitration so that being written of arbitration agreement have been known as a condition for the validity of creation arbitration and stipulate this matter. There is a difference between rules governing on domestic arbitration and international commercial arbitration in the Iranian legal system.

Article 7 of the Law on International Commercial Arbitration notes to the compellingness a document to prove arbitration agreement, but In the Civil Procedure Code, which governs the domestic arbitration, there is no such straightforwardness. This matter has been caused to appear disagreements in this regard in domestic arbitration Iran. The first category believes that arbitration is created based on a written agreement and being written this agreement is a condition of creation the arbitration. The logic of this category is:

1) In public current, the written form of consent is called contract, although this referring is not correct; (Yousef Zadeh, 2014: 46).

2) One of the deterioration cases of arbitration has been announced the written consent in Article 481 of the Civil Procedure Code and this is a counterpart that shows that the legislator has put the principle on being written the contract. Otherwise, it was not necessary, whereas being written the agreement principle has no importance, the form of deterioration declares it written; (Yousef Zadeh, 2014: 46).

3) The Civil Procedure Code, particularly its provisions relating to arbitration has been translated from French law. In the law of that country also the necessity of a document that indicates the conclusion of the arbitration agreement, has been known the condition; (Fakhari, 2008: 120).

4) Inference of being written the agreement to arbitration is not unjustified as the minimum of conditions of form due to practical materials; (Jonaidi, Laya, 2009: 47).

The second category believes that arbitration was not of ceremonial contracts (Mohammad Zadeh Asl, 2001: 403) and may occur even orally (Shams, Abdollah. 2006: 530).

Because Civil Procedure Code of Iran explicitly has not decreed the written form of the arbitration agreement; (Asadi Nezhad, 1999: 68). So the principle of being consensual the contracts does not see an obstacle for its actions and Stipulating some of the Articles of the Law to the "agreement" or "a written document" is the supervisor to most of the matters not a condition for realization of arbitration (Khodabakhshi, 2012: 89). So arbitration agreement should be obtained in the Iranian legal system until it can be applied and the form of this arbitration agreement does not have importance in terms of credit of existence of arbitration. However, it was worthy that Iranian legislator also considered the condition for written arbitration aligned with the law of international commercial arbitration, into the contract internal arbitration. 


\section{Qualification of the Parties}

It is necessary to conclude an arbitration agreement as well as any other contracts that parties have the qualifications of its conclusion. Considering that the main subject of an arbitration agreement is to settle a dispute, and this is usually within the competence of judging governmental authorities so persons can conclude this agreement that have the qualification for action law in these authorities. Hence, not only the qualification of vindication in its general meaning is necessary for the conclusion of this agreement, but it also is necessary to have the qualification for action law; So in addition to incapacitates' protection, bankrupted merchant, which has been prohibited as provided by law from his financial possessions, has no financial litigation right. It is obvious that concluding the arbitration agreement in the non-financial matters are not banned by the bankrupt merchant and therefore there is not a problem.

The remarkable point, is a condition for maintaining qualification during the arbitration process in the arbitration agreement, in other words qualification to action law should be available firstly and constantly until is not disbanded the arbitration agreement. The reason for this matter can be summarized in two cases:

First, that arbitration is an exception and the exception has only existential capabilities within its range, so with the loss of a pillar of this contract, being exceptional the arbitration and it requires that is implemented the principle of Authority of Courts of Justice.

Second, the arbitration is a personal contract and the character under the contract has an important role in it; so if someone loses his/her arbitration qualification, contractual relationship is fragmented and arbitration is practically disbanded. Hence Iranian legislator introduces explicitly 'Death and petrifaction of one of the parties "cause to deterioration of the arbitration in paragraph 2 of Article 481 in the Civil Procedure Code.

\section{The Certain Subject That Is in the Case of Transaction}

Subject of the arbitration agreement, is the arbitration means that the existential reason of this agreement is to create a private dispute settlement procedure with the name of the arbitration.

The characteristic that the arbitration agreement was that merely the existence of this subject to conclude the arbitration agreement is not enough. Since the arbitration forms in a legal relationship current and is a function of it first must be a main relationship ranging from contractual or forcible like a business contract, civil liability and... until consent to arbitration finds meaning to resolve probable disputes or arising from that relationship; in other words, the case of a transaction (the subject of commitment) in the arbitration agreement, is the dispute arises from the primary relation (main); so while the first relationship is apart from the arbitration but due to this that belonging of arbitration is its affiliate (first relationship), consent to arbitration in the absence of that relationship is not possible. Thus, if two people simply for holding similar interests, without the relationship of certain rights, have consent with each other that any dispute which they find in the future, settle it with arbitration, this consent is lack of subject and is not valid (Yousef Zadeh, 2014: 54).

Of course, identifying the subject of the dispute is referred to arbitration, in the public form is sufficient, but must be clear enough to determine the scope of the mission of the arbitrator. In fact, arbitrators should investigate in the range of their mission and proceed to issue a worthy verdict and while the issues which cannot investigate the subjects that are not in their range (Shams, Abdollah. 2006: 525).

In other words, the range of investigation of arbitrators is determined in a subject of the arbitration agreement. However it may be said that because the dispute is not created yet in the future and if possible, so the possibility of an agreement to resolve the difference that there is not yet through arbitration, is incompatible with the General rules of contracts, but legal systems of the world have accepted it and have not known the probability of its occurrence the difference in future as intruder the authenticity of arbitration agreement; because there is a field of disagreement or in other words, a cause of a dispute that is the same main relationship, and this is sufficient to determine the issue of research as waiving the liberty or right for unilateral cancellation the contract has been accepted before the liberty or right to unilateral cancellation research in contracts. According to the subjects mentioned before is worthy like other contracts the subject of an arbitration agreement is precisely determined until does not encounter with a problem in performing.

\section{Legitimacy to Deal}

Direction to ultimate cause and mediate purpose that is motivated a person to conclude the contract (Katuziyan, Naser, 2008, vol. 2: 210). So it must be distinguished between the direction of transaction and direction of commitment.Mentioning the direction in agreement to arbitration is not possible because an agreement to arbitrate is a function of a main relationship and direction in the same main legal relationship must be considered not into the agreement to the arbitration. 
Arbitration can only have a subject; in other words, in this type of contract direction is same as the issue and for that matter cannot imagine a separate issue and independent direction; So if the subject of commercial contract is main or the subject of dispute is legitimate, the arbitration about it is correct and proper and if the subject of the contract is main or the subject of the dispute is illegitimate, arbitration would be illegitimate about it (Yousef Zadeh, 2014: 54). It should be noted that the goal of being legitimate is non-opposition to the public order in general meaning.

\section{Specific Conditions of Arbitration Agreement}

The principle of contractual freedom to the parties of a contract, gives power management of their contractual dispute and control of the judicial process. In the international contractual relations, this freedom appears often in the form of a contract or agreement that is a donor of eligibility to the national court or private tribunal proceeding (Bagheri, Mahmoud, 2007: 62).

The freedom of will of parties in commercial arbitration would empower them to guide and manage the arbitration current as consider them appropriate and this feature has been caused the procedure of arbitration be desirable for the settlement of the international disputes (Kakavand, 2012: 1). The same principle requires that specific conditions or the same content of the arbitration agreement is determined by the conflicting parties. The most important cases that the conflicting parties have agreement in them in the arbitration agreement, and in the case of disagreement, often legal systems in the subject of arbitration have expressed as a supplement of will, Specific conditions constitute arbitration agreement that will be noted them in following.

\subsection{Competence of Arbitrator}

In terms of civil procedure, Competence has been defined, "judgmental right and assignment of authorities in dealing with legal problems to the rule of law" (Shams, Abdolah, 2006, vol. 1: 383).

There is right to be arbitrator as a pillar of this definition provided by law because as soon as anyone born alive enjoy civil rights, and the right to be elected as an arbitrator, is a civil right; But the duty of arbitrator in investigating the dispute that has been referred to him/her, when is created that he/she accepts the arbitration; in other words, in addition to the arbitration agreement between the conflicting parties to refer the dispute to arbitration, the arbitrator must accept requirement of the parties has been included in the arbitration agreement, until is obliged to accept the investigation.

Of course, this duty is loaded over the arbitrator in the rule of law with this difference, that in governmental proceeding directly creates the duty of investigation, but in the arbitration, by acceptance arbitration by the arbitrator and legal obligation to fulfill the commitment of is obligated to investigate and resolve the dispute. The jurisdiction of the arbitrator in the arbitration agreement is debatable for two aspects: personal jurisdiction and subject matter jurisdiction.

\subsubsection{Personal Jurisdiction of Arbitrator}

The mean of personal jurisdiction of the arbitrator is the same characteristics that a person must contain in order to select as an arbitrator (Pour Rashid, 2005: 44). Basically, all persons can be appointed as arbitrator. Of course, people can benefit from their social rights that are qualified to vindicate. Hence the conflicting parties can select anyone who has desirable properties, as arbitrator and there is no limitation with the exception with legal specified cases in this field. Among the most important characteristics is his/her independence. That a person must contain until can be selected as an arbitrator and finally issue the vote in accordance with justice and fairness so that is being protected from next aggression of protester. The meaning of independence of an arbitrator in the arbitration proceeding is that arbitrator in terms of material or other terms is not connected to one of the conflicting parties. In fact, the existence of previous or current, professional or social business relationship of the arbitrator with one of the parties or their legal counsel is the cases of lack of his/her independence (Tapman, Michael, 1990).

In other words, independence of arbitrator means that the arbitrator or arbitrators must have no blood or marriage ties, a subscription or conflict of interest with any of the parties. The arbitrator or arbitrators who previously has done a service for one of the parties or currently are doing a task for one of them cannot be called independent; or if the arbitrator has an interest In the subject of the dispute or be partner or contribute in the material interests of one party, also is not considered as independent (Kech, 2007).

Guarantee of implementation this personal property of the arbitrator in the time range before the start of the arbitration process to its completion, amendment of arbitrator and after the completion of arbitration current, set aside the award is because he is independence. The next point about it is the equality of natural or legal persons for selecting as an arbitrator. It is obvious that in the legal persons that have been formed to settle the dispute, 
also have competence however that finally a natural person is acted to the arbitration on behalf of it. As the judicial branch as an independent legal person and on behalf of government has the task of settle disputes between the parties. Final point with regard to personal jurisdiction of arbitrator is that if the conflicting parties have not used of their rights in arbitration agreement to select the arbitration and cannot agree after incidence a dispute in this regard, the positive laws of countries have predicted strategies to start or continue the arbitration process.

\subsubsection{Subject Matter Jurisdiction}

As mentioned in the previous issues, the nature of Competence is a combination of the right and duty; so the meaning of subject matter jurisdiction, is whatever that arbitrator in his/her investigation can and should deal with it; in other words, the scope of arbitration proceedings will be investigated in the discussion of subject matter jurisdiction of the arbitrator. The basic point that arises in the arbitration is an investigation jurisdiction of the arbitrator to his /her competence to resolve the dispute. If the dispute arises between the conflicting parties on the subject and the scope of the arbitration proceeding, in other words, whenever the subject matter jurisdiction of arbitrator occur dispute between them, arbitrator has the possibility to investigate the principle of the jurisdiction in the matter referred to her/him has been interpreted it to "Competence".

The term is attributed to the Germans, and has been interpreted in various forms by Iranians jurists. "The competence than Competence" (Jonaidi, Laya, 2009: 68) "Competent in determination the jurisdiction" (Seifi, 1998: 62), "The authority than Competence" (Abedi, 2006: 97) and "Independence in announcing the competent" (Khodabakhshi, Abdollah., 2012: 299) are four different interpretations of this rule.

Competence of the Court's jurisdiction of arbitration about commenting about its competence was known as an inherent power for arbitration so that this issue has been clearly stated in the rules of all international organizations of arbitration (Redfern \& Hunter, 2005: 215).

Since the arbitral tribunal is allowed to determine its own jurisdiction based on this rule, may this competence seems unreasonable at first sight and if the arbitral tribunal has no competence. If the court does not have competence, how has investigated to its Competence?

The rule of Competence has been recognized as a universal rule in arbitration rules in the most countries and finally, because the legislator has allowed to the arbitral tribunal, it can investigate its competence (Greenberg et al., 2011: 215). Of course, this statement is contrary to the opinion of the author.

Because the main basis of this competence is optional that the parties have granted in the arbitration agreement to the arbitrator and, of course, the has also been considered this issue for legislators, in other words, when the will of parties of arbitration agreement has granted to settle disputes through arbitration, by the first method is granted to the decision of arbitration about having competence or no competence over the referred matter.

Based on the rule of rational and legal "permission in an object is the permission in the materials," When give the option to settle the personal dispute, this authorization requires also to give the authorization with regard to investigate the competence in the referred matter; so Competence is the basis of competence of mutual consent of the conflicting parties and is considered as outcome of being contractual the arbitration. One of the basic tenets in the fundamental principles of judicial independence is the exclusive jurisdiction of the judgmental reference to decide about investigating the legal jurisdiction to investigate the matter referred to that reference. Since the arbitration is also considered the judiciary institution, must have the independence to be able to deal with hostility season. Hence has been said that the arbitrator has absolute competence to examine his /her competence and there is no guarantee of performance to the requirement of an arbitrator to prohibit or prescribe his/her investigation; so the executive guaranty should be deferred until after the issuing the verdict, in case of violation of the rules of competence, his/her action would be ineffective with the annulment of the vote (Khodabakhshi, A., 2013: 302).

\subsubsection{Language of Arbitration}

The meaning of language in arbitration is the language of investigation in arbitration. When the parties to a dispute speak with a language in the arbitration, the issue of determining the language finds importance that the conflicting parties talk to the two or more different languages. The problem does not occur in the process of handling of the arbitrator or arbitrators. The arbitrator or the arbitral tribunal should be able to listen to the statements of the parties, set the agenda and finally issue the verdict. When the conflicting parties do not have a common language, the language of arbitration proceedings must be determined.

Determine the language of investigation is not out of three modes: 
First, the parties refer to the language of the investigation in addition to the arbitration agreement, Second, the parties agree to this matter in the arbitration agreement that is set before the start of proceeding; third that the language of arbitration has not been determined not in the arbitration agreement and not has been agreed to it in the arbitration agreement.

In two moods first because of the autonomy principle of the will and the principle of arbitration contractual, any language that the parties selected is put as the language of investigation. The basic problem occurs in the third. In this case, the arbitrator or arbitrators shall determine the language of the proceedings before the arbitration act.

The arbitrator or arbitrators are not totally free in choice of language in proceedings and for this it is necessary to pay attention to the common will of the parties in the course of legal transactions and if it is necessary should give the parties an opportunity to comment.

Moreover, the language of negotiation and contract and the language used in the document are exchanged and are of other issues that need to be considered in determining the language of the proceedings and investigation. For example, if the contract that contains an arbitration provision is set in both English and Arabic languages and in that contract, the arbitrator was selected that the English language is his/her spoken language, it can be understood that the parties have intended to admit English as the language of their proceedings and investigation. One of the parties may be able to speak two languages, but the other side only may have mastered a language. For example, when a side is Chinese and can speak both Chinese and English languages and the other is from Nigeria and can speak only in English, the arbitrator will choose the English language as the language of proceedings and investigation. The thing that is important is to implement the arbitration and dispute settlement in the best possible way. Thus, in the present example, selecting the English as the language of the proceeding and investigation does not create inequality between the parties. When the language of the arbitration is determined, all the documents submitted to arbitration should be to determined language, so for example if English is selected as the language of proceeding and investigation, all documents also must be in English , and if the document is in another language, must then be translated into the language of proceeding and investigation. Of course, this task is not the umbilical of presentation the original document that is translated (M. Klotz, 2008: 289).

In the rules and regulations related to arbitration, selecting the language of the arbitration and also the duty of the arbitration to determine the language of the arbitration (in the case of lack of language) also have been given at the disposal of the parties of arbitration agreements. This subject reflects the principle of contractual freedom and also is the origin of being contract the arbitration. Article 21 of the International Law Commercial Arbitration of Iran is addressed and investigated this issue explicitly.

According to the Swedish doctrine, in the case of not determine the language, the language of the proceedings is determined by the nationality of the parties. If the parties are in Swedish, the language of investigation is a Swedish language in the arbitration proceedings and if they have differences in nationality, the English language will be selected as the language of the proceedings. Of course, this occurs when no agreement is done to determine the language.

\subsubsection{The Time of Arbitration}

One of the fundamental differences between private proceedings and governmental proceedings there is no time limit to reach a conclusion at the governmental proceedings. The judge is trying to reach the truth based on the presented evidence Hearings will continue until the result satisfied the conscience of the judge in the raised subject. After the end of the hearing, the judge announced the verdict and tries to issue the vote. Humans are interested that do not have intellectual engagement in their community life and in the event of a dispute the calmness with another hurt, the sooner they return to the peace. Therefore, the time of addressing and resolving differences among individuals is very important in a society.

The purpose of arbitration period is the period prescribed for the referee's opinion, not every time. Judges can only issue the vote at the time that the parties have been designated for them, and with the passing of the deadline, they will lose their jurisdiction; in other words, a time of arbitration is an expression of the principle of autonomy of the parties in the arbitration agreement. The time is a container that arbitrator must do in which all necessary steps, including obtaining the opinion of expert and cannot be claimed that the deadline is only for issuing the verdict and its starting is from the time that are provided all the arguments of the parties and the arbitration and the needed results. Start the arbitration is a border of the determined time for judgment and obtains this issue is important (Khodabakhshi, 2012, 302).

Because if an arbitrator issues a verdict outside the prescribed period, actually acted contrary to the common will 
of the parties and at the result his/her vote would be ineffective. Qualifying of the starting the time of arbitration and follow by that issuing the verdict within or outside the time of arbitration is a subject matter for arbitration that in the case of conflict and with the claim of one of the parties shall be determined by the competent court.

\subsubsection{Arbitration Costs}

Decision making regarding costs of dispute settlement, especially in commercial disputes that often the numbers of differences are huge, it is considered as the advantages of arbitration. When the parties to the dispute can agree in principle of referring the dispute to arbitration, surely it costs also can determine and pay with mutual consent. Determine the amount of the fee of arbitrators that also requires the constant of the arbitrator, the way of paying and the share of parties of these costs are the cases that persons can agree to them in case arbitrations. Therefore, Articles 497 and 500 of the Civil Procedure Code of Iran are considered valid the agreement of the parties on the amount and method of payment the cost and are considered it the criteria for determining the cost.

In arbitration organizations, usually the mount of costs and method of paying it have been stated within the rules and regulations of organization, but in the case arbitration, the parties can agree on arbitration costs. Considering that the fee of the arbitrator has been seen in these costs, if the referee agrees to receive less remuneration, there is not a problem in agreeing with him/her, so even in arbitration institutions as well as parties can adjust arbitration costs through agreements with third parties to arbitrator. Decision making about the way of paying for arbitration costs in the arbitration agreement is an option which increases the speed of the proceedings in arbitration. Because in the event of incidence a dispute, the parties will be less willing to compromise. The experience has been shown that there is a direct relation between the expressions more details about the way to implement the arbitration agreement and the speed in arbitration proceedings. That means that whatever more details are stated in the arbitration agreement, differences will be less on the implementation of agreement and dispute settlement and therefore resolving the differences will be quicker (Bühring-Uhle et al., 2006: 98).

\subsubsection{Location of Investigation}

Generally, the parties are free to determine their location to investigate in arbitration proceedings. To determine the location of the arbitration may be conducted in a contract or to be determined after incidence a dispute. In any case, determining the location must be done until exist the possibility of implementing the arbitration proceedings. If the parties have not agreed to the location of investigation, inevitably must be determined the place for investigation. The answer to this question: Where should be the place of investigation particularly is not easy and simple in international commercial arbitration (Redfern \& Hunter, 2005: 270). In this case, the arbitrator must first discover the will of the parties.In the case of lack of discovery should select the most appropriate location according to the governing situation and announce to the parties. The most appropriate place to judge is determined of the circumstances governing to the parties, including the location of concluding the main contract and the arbitration agreement, the place of execution the original contract, contract language and... (Šarčević, Petar (editor), 1989: 116). Determine the location of the investigation in the arbitration agreement is of the cases that are effective in a quick investigation of the conflict of the parties. Because the arbitrator instead of allocating time to locate of investigation can more quickly resolve the dispute. So can be suggested to people who are willing to resolve their dispute through arbitration, to determine the place of implementing the arbitration in the arbitration agreement.

\subsubsection{Number of Arbitrators}

Parties to the dispute are free to choose the number of arbitrators with their agreement. They can choose one or more as a dealing arbitrator. In most cases, the parties are trying to consider the number of arbitrators until does not exclude the possibility of arbitration. If they compromise a person's judgment, his/her opinion is overwhelming controversy. If two or combination of even numbers are determined, if all comments are the same, the problem does not occur but when a disorder is created in an investigation that the number of agree and disagree arbitrators be equal with a comment. In this case, if the parties do not agree to the addition of another arbitrator or jury or do not accept a view of the raised comments, virtually ruled out the possibility of resolving disputes by arbitration and arbitration is dissolved. Therefore, although the parties are free to determine the number of arbitrators, but it is recommended to select the number of arbitrators so that is followed the probability of not being able to handle. Supplementary rules of countries in the field of arbitration and regulations of the arbitration of arbitration institutions. If the number of arbitrators is not determined and lack of the parties' consents to their number, have selected a three-member arbitration rule so that each of the parties selects a specific arbitrator and another arbitrator is chosen in the form of mutually acceptable or by the two specific arbitrators.

However, in the case of the number of claimants or defendants, this question is raised that does each one of them 
have the right to choose a specific arbitrator or all of the claimants together, and do all the defendants together select a specific challenge?

In any case a dispute is raised and considered on the principles of the proceedings and in other words the subject of dispute in each dispute is one thing. Now one person or more may claim it or subject fights are raised against one or more person; so the parties are determined to validate the subject of dispute. When the number of claimant or defendant is more than one person, parties to a dispute are divided into two groups and each of the parties is placed in a group.

So the idea that each of the parties for a dispute can choose an arbitrator for themselves, so that will be an arbitrator in the number of people in fights, it is contrary to the common will of the parties is not possible. Then the prime opinion is rejected and all defendants together, and all the defendants together will have a specific arbitrator and the third arbitrator (the referee) will be determined as prescribed in the regulations governing on the arbitration. Another question that arises is that the arbitrator of plaintiffs or defendants determines themselves or necessarily the other entity must determine this arbitrator? Regulations, governing the arbitration stance are different in this regard. Paragraph 6 of Article 11 of the Law of International Commercial Arbitration, has put the selecting the arbitrator by the parties however the number of claimants or defendants are numerous; Of course, if there is no agreement on an arbitrator by them, determine the arbitrator is the responsibility of "General Court is located in the center of the pronince that the place of arbitration is located in it and as long as the place of arbitration is not specified, it is the responsibility of the Tehran public court. Court decisions in these cases are final and without appeal.

\section{Conclusion}

Being exceptional the arbitration institution requires that its formation is done under the agreement of the will of parties in the form of the arbitration agreement. The nature of the arbitration agreement is a contract and like all contracts has general and specific conditions which were discussed in this article. The results that have been obtained from study about it are as follows:

1) Most legal systems consider the arbitration as a ceremonial contract and have known the writing as a condition to create it, but a domestic arbitration law of Iran without formalities and International arbitration is ceremonial. The good of society and Works of arbitration award requires the legislator amends these provisions in domestic law.

2) To conclude the arbitration agreement is not only necessary the qualification of enjoyment in its general sense, but it also needs the qualification of action law. Moreover, according to being exceptional and personal this contract, the qualification of action act must be firstly and constantly. Hence the legislator explicitly introduces 'Death and Protection, one of the parties "ta cause to decline arbitration.

3) Subject of the arbitration agreement, is the arbitration, which means that the existential reason of this agreement is establishing a private dispute settlement procedure with the name of the arbitration. Since the arbitration is formed in a legal relationship and it is a function of it, first must there be the main relationship, whether contractual or forcible until mutual consent, finds meaning to arbitration to solve a potential dispute or contingent by that relationship.

4) It is not possible to mention the direction in the agreement to arbitration because the agreement to arbitration is a function of the main relationship and the direction should be considered in the same legal main relation rights not to agree to arbitration.

5) The qualification of the arbitrator is in proceedings arising from the integration of the wills of the parties and itself. Parties to the dispute except cases specified by law have no limitation in the selection of persons as arbitrator and in this regard, there is not the difference between natural and legal persons. In addition jurisdiction of investigation the arbitrator has been included to his/ her jurisdiction in dispute settlement in the will of the parties and theartibrator is able to handle its own jurisdiction in the matter referred to it that has been interpreted as the "competency".

6) It is important to determine the language of arbitration when the parties to the dispute communicate in two or more languages. In this case, the arbitrator or arbitrators shall determine the language of the proceedings before the arbitration process, and in this matter, it is necessary to pay attention to their common will in the course of legal relations. When the arbitration language is determined, all the documents submitted to arbitration should be in determined language.

7) The purpose of arbitration period is the period prescribed for the opinion of arbitrator and not every time. Arbitrator can issue the vote only in deadline that the parties have assigned to them, and with the passing of the 
deadline, will lose their competency. Obtaining the starting the time of arbitration and followed by that the issue of vote within or outside the time of arbitration is subject matter that in case of conflict and the claim by one of the parties must be diagnosed by a competent court.

8) The decision on the costs of the settlement the disputes and place of arbitration is one of the significant differences between arbitration and government proceedings. When parties the dispute can agree in principle of referring the dispute to arbitration, certainly in terms of location and handling costs can also agree.

The parties in dispute are free to choose the number of arbitrators also by their agreement. Complementary legislations of countries in the field of arbitration and arbitration rules of arbitration institutions, in the case of not to determine the number of arbitrators and the lack of consensus of the parties to their numbers, have adopted a three-member arbitration rule so that each of the parties to the dispute choose a specific arbitrator, another arbitrator is chosen in the form of mutually acceptable or by two special arbitrator.

\section{References}

Abedi, M. T. (2006). Jurisdiction and judgment (analysis on a decision on the question of eligibility). Hququbynalmlly Magazine, (35).

Asadi Nezhad, M. (1999). Iran international commercial arbitration and UNCITRAL. University of Gilan, Rasht.

Bagheri, M. (2007). Qzayybynalmlly about freedom of the parties in determining the jurisdiction of the place of arbitration Tjarybynalmlly. Journal of Law, Faculty of Law and Political Science at Tehran University, $37(3)$.

Bühring-Uhle, C., Kirchhoff, L., \& Scherer, G. (2006). Arbitration and Mediation in International Business. Netherlands, Kluwer Law International, p.98.

Chovancova, K. (2007). Arbitration in Slovakia: Breaking new ground, Bratislava, Slovak Republic. Comenus University, published in: International Arbitration and Mediation - From the Professional's Perspective, edited by Alibekova, Anita, Carrow, Robert, Salzburg Austria, Yorkhill law publishing, p. 104.

Fakhari, A. H. (2008). Arbitration means to abuse, criticism of judicial decisions, the first book, the judiciary Research Center Tehran.

Greenberg, S., Kee, C., \& Weeramantry, J. R. (2011). Internatinal commercial arbitration: An Asia-Pacific Perspective ( $1^{\text {st }}$ ed.). New York, Cambridge University Press, pp. 215-216.

Jonaidi, L. (2009). Review of Comparative Law Arbitration Act Tjarybynalmlly 26.06.76, published by the Faculty of Law and Political Science at Tehran.

Kakavand, M. (2012). Tjarybynalmlly free will of the parties in the arbitration, the Arbitration Center of the Iran Chamber Tehran.

Katuziyan, N. (2008). General Law Corporation Published: Tehran.

Kech, C. (2007). Judges mayhem standards and procedures (Translator: Abraham flowers, AR). Legal Services Office of International Law Journal, (36).

Khodabakhshi, A. (2012). Arbitration and litigation relating to its rights in legal proceedings. Publishing Corporation Published: Tehran.

M. Klotz, J. (2008). International Sales Agreements: An Annotated Drafting and Negotiating Guide. Netherland, Kluwer law international, p. 289.

Mohammad Zadeh Asl, H. (2000). Arbitration in Iran's rights. Phoenix Publishing Tehran.

Pour Rashid, Z. (2005). About judgment, Master thesis in Private Law, Tehran University.

Redfern, A., \& Hunter, M. (2005). Law and Practice of International Commercial Arbitration. London, Sweet \& Maxwell Limited, p. 215.

Sadr Zadeh Afshar, S. M. (2005). Civil and Commercial Procedure Code. published by University of Tehran.

Šarčević, P. (Ed.). (1989). Essays on International Commercial Arbitration. London, Graham and Tortman Ltd. pp. 115-116.

Seifi, S. J. (1998). Iran Tjarybynalmlly arbitration law in line with the UNCITRAL Arbitration Model Law, Law Journal office Hqvqybynalmlly Islamic Republic of Iran.

Shams, A. (2006). Code of Civil Procedure (Vol. 3). The Drake: Tehran. 
Tapman, M. (1990). Injury and disqualification of international commercial arbitration (Translator: Myrfkhrayy, MJ), Tehran, International Journal of Law office of legal services, (12).

Yousef Zadeh, M. (2014). Arbitration procedures. joint-stock company Published: Tehran.

\section{Copyrights}

Copyright for this article is retained by the author(s), with first publication rights granted to the journal.

This is an open-access article distributed under the terms and conditions of the Creative Commons Attribution license (http://creativecommons.org/licenses/by/4.0/). 